\title{
István Örkény: la brevedad y el absurdo
}

\section{Aurora PIÑEIRO \\ Universidad Nacional Autónoma de México}

\begin{abstract}
Este artículo propone una lectura de la obra narrativa del escritor húngaro István Örkény, centrada, de manera específica, en sus colecciones de cuento brevísimo, publicadas a partir de los años sesenta. El análisis de los textos se lleva a cabo aquí desde las convenciones del realismo fantástico, y se hace énfasis en la manera como el absurdo y lo grotesco, en complicidad con la estética mencionada, vehiculan una crítica de orden político, entre otros, en una época de marcada censura.
\end{abstract}

PALABRAS ClAVE: Örkény, cuento brevísimo, absurdo, literatura húngara, realismo fantástico.

This article offers a reading of the narrative corpus produced by Hungarian writer István Örkény, in particular, the flash-fiction or microfiction collections published during the sixties as well as in posthumous editions. Örkény's works are analysed here from the perspective of the conventions of Fantastic Realism and an emphasis is made on the way in which the absurd and the grotesque develop a complicity with the afore mentioned aesthetics in order to facilitate a critique, among others, of the prevailing political system of the time, which was strongly characterized by intolerance and censorship.

KEY WORDS: Örkény, flash-fiction, absurd, Hungarian literature, Fantastic Realism.

Así saco de lo absurdo tres consecuencias, que son mi rebelión, mi libertad y mi pasión.

Albert Camus

Las atmósferas sofisticadas de los cafés de la ciudad de Budapest se vieron enriquecidas por la presencia de las llamadas "islas Örkény", mesas de lectura instaladas en dichos espacios públicos, durante el año 2012, como parte de las actividades conmemorativas del centenario del nacimiento de István Örkény (1912-1979), uno de los escritores húngaros más importantes de la segunda mitad del siglo XX. Visitantes y parroquianos pudieron recorrer así, en traducciones a diversos idiomas, las páginas de una escritura que retrata las contradicciones de la Europa de la posguerra y, en particular, 
de la vida en Budapest, la ciudad con la que el autor estableció una doble relación de complicidad literaria y crítica despiadada.

Más allá de las fronteras húngaras, Örkény es conocido, sobre todo, como dramaturgo. De manera específica, se le identifica como el autor de Tóték (traducida al inglés como The Toth Family, y al español como Un comandante en casa) y Macskajátéc (Catsplay y Juego de gatas, respectivamente), obras que confirmaron su carrera como uno de los grandes exponentes de la estética del absurdo centroeuropeo. Sin embargo, en Hungría, desde mediados de la década de los sesenta, el autor gozó de gran fama como prosista, y ésta es una de las razones por las que el presente artículo está centrado en su producción narrativa, en particular, en sus dos colecciones de cuento brevísimo tituladas Egyperces Novellák (One Minute Stories o Cuentos de un minuto) y More One Minute Stories (Más cuentos de un minuto), ${ }^{1}$ que lo convirtieron en el creador de un subgénero, al mismo tiempo que de todo un modo literario, el del realismo fantástico, como lo define Zoltán András Bán. Además de revisar algunas de las características formales de las obras mencionadas, analizaré la manera en que Örkény utiliza lo grotesco y las inversiones paródicas como una estrategia de resistencia política ante una realidad histórica que sólo era tolerable por la vía de un humor inevitablemente negro. La escritura de Örkény dio cuenta de un momento de crisis y represión nacionales desde una estética en tensión con lo mimético, mantuvo a raya lo panfletario y los sentimentalismos, a la vez que denunció las contradicciones de los discursos totalizadores y las llamadas grandes narrativas. Lo anterior nos permite ubicarlo en el contexto de lo que hoy designamos como pensamiento posmoderno.

Los "cuentos de un minuto" fueron definidos por Örkény, en las "Instrucciones de uso" del primer volumen, como historias cuya brevedad permite que el lector las haga suyas en el lapso de tiempo que nos toma la preparación de un huevo tibio o la espera antes de que una llamada telefónica sea contestada. Son textos que pueden leerse en cualquier estado de ánimo; de pie o sentados; en condiciones climáticas favorables o desfavorables (1995: 11); ${ }^{2}$ así enuncia Örkény la construcción de un ars poetica, con un lenguaje que rechaza la solemnidad y los criterios literarios estrechos, y nos entrega las primeras cincuenta y seis historias, con instructivo y biografía de autor (de un minuto). Su escritura está marcada por una economía de lenguaje que se manifiesta no sólo en la extensión de las historias, que puede acotarse a un párrafo breve, sino en la desnudez de la prosa, caracterizada por un mínimo de adjetivación u otros recursos descriptivos. En muchas ocasiones, se acude al diálogo como modalidad discursiva

\footnotetext{
${ }^{1}$ Esta última es una compilación póstuma, del año 2006, con textos seleccionados por Judith Sollosy, a partir de las ediciones de 1977 y 1985 de Egyperces novellák; de Búcsú, Kiadatlan novellák, de 1989, y de Egyperces novellák, de 2001.

${ }^{2}$ Utilizo la edición de la obra en inglés, con la traducción realizada por Judith Sollosy, ya que esto permite acercar los textos a un número más amplio de lectores, quienes, además, encontrarán menos obstáculos para la adquisición de la misma en dicha lengua, dada su distribución en un número mayor de países. Las citas en inglés se acompañan de la traducción al español, mía, en nota a pie de página. Las traducciones al español de otras fuentes citadas que aparecen en el cuerpo de este artículo también son mías.
} 
dominante, elección que pone en evidencia la experiencia del autor como dramaturgo, y permite la construcción de una historia posible, a partir de la interacción entre los personajes, con parlamentos breves y filosos. Un ejemplo de lo anterior es el cuento "In Memoriam Dr. H. G. K.", donde un doctor en letras, conocedor de la lengua y literatura alemanas, intenta establecer una conversación con un guardia alemán, al mismo tiempo que cava una tumba destinada a alojar la carcasa de un caballo. La comunicación se ve frustrada por el desconocimiento de la literatura alemana de parte del guardia, quien asume que el prisionero o subalterno está tratando de humillarlo por su ignorancia de la cultura propia, y lo ejecuta:

"Who're them guys?" the guard growled, louder than before.

"Poets," Dr. H. G. K. said. "But Schiller. Surely you have heard of Schiller?"

"That goes without saying," the German guard nodded.

“And Rilke?" Dr. H. G. K. insisted.

"Him, too," the German guard said and, turning the color of paprika, shot Dr. H. G.

K. in the back of the head $(1995: 27){ }^{3}$

Con un mínimo de recursos lingüísticos y literarios, el autor empuja al lector a completar la escena: deducimos que se trata de un intelectual, probablemente judío, en un campo de trabajo o exterminio, en el contexto de la Segunda Guerra Mundial y geoculturalmente vinculado al mundo húngaro por la referencia, en la breve intervención de una voz narrativa, al rojo como el color más común de la páprika. Así, a la brevedad de los textos, se une la importancia de la participación del lector como el elemento activo fundamental en la construcción de significados posibles, otro requisito señalado por Örkény en las citadas "Instrucciones de uso" además de, agrego aquí, la importancia de los títulos, que el autor describe como parte orgánica de los textos. En el cuento recién citado, el hecho de que el título indique que la obra está dedicada "a la memoria de" un intelectual, cuya identidad no conocemos, implica un posicionamiento frente a lo que será narrado: el intelectual, representativo de las muchas personas de ciencias y letras que fueron condenados a trabajos humillantes o asesinados durante el periodo en cuestión, es un personaje que vale la pena recordar, frente a la brutalidad del guardia, quien "gruñe" y es poseído por una ira incontrolable y asesina. Los títulos, como recursos paratextuales, se vuelven parte indispensable de la obra, y establecen con el cuerpo de la misma relaciones de complicidad, contradicción y continuidad, entre otras. El narrador de las instrucciones insiste en que "the author strove

\footnotetext{
3 “¿Quiénes son ésos?”, gruñó el guardia, con más estrépito que antes.

"Poetas," dijo el Dr. H. G. K. "Pero Schiller, ¿seguro que habrá oído de Schiller?"

"De eso ni hablar", asintió el guardia alemán.

“¿Y Rilke?” El Dr. H. G. K. insistió.

"Él, también", dijo el guardia alemán y, con el rostro enrojecido como la paprika, le disparó al Dr. H. G. K. en el cráneo.
} 
for brevity, which put a special burden of responsibility on him when choosing the titles for his stories, of which they form an organic part" (Örkény, 1995: 11). ${ }^{4}$

Julio Cortázar, quien también concebía al cuento contemporáneo como una "máquina infalible destinada a cumplir su misión narrativa con la máxima economía de medios", solía establecer la diferencia entre la novela y el cuento con un símil relacionado con el mundo del boxeo. El argentino señalaba que "en el combate que se entabla entre un texto apasionante y su lector, la novela gana siempre por puntos, mientras que el cuento debe ganar por knock-out" (1994: 47). En Cuentos de un minuto, el lector queda perplejo o en estado de shock frente a la denuncia de los abusos y el absurdo de las condiciones de vida en una Hungría que ya había pasado por la Segunda Guerra Mundial, por la Revolución de 1956, el contexto más amplio de la Guerra fría, y diversas variantes de lo dictatorial. Los dobles discursos políticos y morales, las farsas del poder se ven exhibidas ante los ojos de un lector que es obligado a formar parte de la historia, como testigo o como actor. Son varios los textos que terminan con un disparo final (ver, por ejemplo, "Autoescrutinio"), un tiro de gracia formal y de contenido que, aunado a la desnudez de la prosa, al golpe de intensidad que lo breve propicia, hacen casi insoportable la crudeza de lo narrado. El dictum cortaziano se torna aquí implacable.

A la brevedad, los títulos como componente orgánico y la participación activa del lector, tenemos que agregar, para completar la definición de "cuento de un minuto", la naturaleza híbrida de las composiciones. Para Péter Esterházy, estamos ante una combinación de "anécdota [...], aforismo, anotación, object trouvé, relato, broma y parábola" (Esterházy, 1995: 11). La presencia contaminante de más de un tipo de discurso en los textos nos habla del carácter transgresor de las obras y la intención de desafiar o hacer elástica la definición misma de cuento. Para Esterházy, estas creaciones son "poemas post-Auschwitz que no pueden ser escritos" (13). El coqueteo con los recursos propios de la poesía se hace patente en textos donde la distribución de las palabras en la página crea un juego plástico que refuerza el contenido. En “Gravepost", por ejemplo, las palabras forman la silueta de un tipo de lápida, en este caso la cruz mortuoria que señala el lugar de "reposo" de un fallecido. Además, el doble juego del título en inglés puede remitir a lo grave y a una acepción de "post" como "comunicación": el poema se anuncia como una comunicación grave, un texto donde se explora el tema de la muerte, asociado a la oscuridad y el origen de los miedos humanos, al mismo tiempo que las palabras impresas configuran la silueta de la mencionada cruz mortuoria.

En el caso de "Empty page" o "Página en blanco" que, junto con "Gravepost", pertenece a Más cuentos de un minuto, el texto es una página vacía, con sólo una nota a pie que reza: “*These "empty pages" are about nonexistent things or else things that

4 “[...] el autor se esmeró por lograr la brevedad, lo cual le puso una carga extra de responsabilidad sobre los hombros al momento de elegir los títulos para las historias, con las cuales forman un todo orgánico". 
exist, but about which the author has nothing to say" (Örkény, 2006: 114). ${ }^{5}$ Aquí el juego irónico se abre a diversas posibilidades interpretativas, entre las que podemos señalar la denuncia de los discursos políticos que niegan las ineficiencias o las injusticias, y suponen que eso las hará invisibles o atribuibles a un error de percepción del observador. También cabe aquí lo contrario, las "cosas existentes", pero sobre las que el autor prefiere guardar silencio, o ante las que se aceptan las limitaciones del lenguaje como vehículo para la representación. A esta lectura se afilian críticos como Margit Koves cuando afirman que los Cuentos de un minuto son "una reflexión filosófica sobre el lenguaje y lo inadecuado del discurso en la interacción humana" (Koves, 1997: 2151). Pero Örkény va más lejos y se une a otros autores de la época, como Beckett, en su preocupación por la contradictoria naturaleza del lenguaje como vehículo sofisticado y, al mismo tiempo, limitado para comunicar la compleja experiencia humana. De ahí que, al igual que Beckett, busque formas de enunciación que violentan la lógica discursiva, como el absurdo o las inversiones paródicas (y su preferencia por lo grotesco), además de las dislocaciones del sentido de la proporción espacial, como uno de los recursos que configuran la estética del realismo fantástico.

Zoltán András Bán, en "Fantastic Realism. Istvan Örkény’s One Minute Stories", afirma que Örkény es el creador del realismo fantástico. En un primer momento, Bán hace referencia a Todorov, y a su ya clásico estudio sobre lo fantástico, donde el teórico señalaba que en la literatura fantástica del periodo modernista, y en buena medida gracias a Kafka, los valores literarios sufrieron una inversión: lo fantástico se tornó normal y viceversa. Esta lógica de inversiones, que facilita la presencia de lo absurdo, es utilizada por Bán como primera referencia para analizar la solución que Örkény encontró para representar en sus textos una realidad fantástico-kafkiana, en una época en que las políticas culturales habían exigido, primero, un apego al realismo socialista y, en la era Kádar, la sumisión al "realismo crítico", en una nación donde los escritores estaban obligados a referirse a la Revolución de 1956 como una "contrarrevolución". Según Bán, "lo que Örkény encontró en Cuentos de un minuto fue una manera de sortear el realismo y la representación directa que, de hecho, llevó los textos de vuelta a otra idea de realismo, por medio de un golpe de genialidad" (Bán, 2008: s. p.). Esta chispa o golpe de genialidad fue la estética del realismo fantástico, un tipo de escritura que parte de lo realista, lo distorsiona, y nos devuelve un retrato de la realidad que, sin pretender ser de clave mimética, resulta paradójicamente contundente y afirma, una vez más, la capacidad de lo fantástico para desmantelar nociones establecidas y llevar a cabo un análisis de calado social o filosófico: "Örkény aportó algo radicalmente nuevo a la literatura al crear el realismo fantástico, que parecía ser la única solución formal válida y valiosa para dar cuenta de una realidad que se había vuelto completamente fantástica y absurda" (2008: s. p.). Lo absurdo y lo grotesco son, de hecho, dos recursos mencionados por Bán, quien cita, del ars poetica del autor, lo que Örkény

\footnotetext{
5 “*Estas 'páginas en blanco' tratan de las cosas inexistentes o, también, de cosas que existen, pero sobre las que el autor no tiene nada que decir".
} 
entendía como la función de lo grotesco: "Lo grotesco sacude los cimientos de lo que se proclama como válido en términos absolutos, pero no lo sustituye con otra idea de validez. Coloca signos de interrogación donde antes se encontraban los puntos y aparte - no concluye o finiquita, sino que abre nuevos caminos, empuja en nuevas direcciones" (Örkény apud Bán). Esta noción comulga con uno de los postulados básicos de las estéticas posmodernas: no se trata de sustituir un sistema de valores absolutos por otro, sino de generar discursos que no se autopromulguen como definitivos, que se sepan temporales, sometidos a cambios constantes, y celebren su inestabilidad. ${ }^{6}$

De entre las muchas estrategias del realismo fantástico hay una que, a mi parecer, Örkény utiliza de forma magistral. Se trata de los cambios en la perspectiva que distorsionan el sentido de las proporciones espaciales y los referentes temporales dentro de la historia, como ocurre en "Aiming for the Salt Cellar" o "Apuntando hacia el salero". El cuento inicia con la narración de una comida familiar, en una casa húngara, en honor de una visitante alemana: una atractiva estudiante de intercambio, de dieciséis años de edad. La familia extensa se desvive por atender a la visitante, por mostrarle los encantos de la cultura y el arte culinarios húngaros, por hablarle en alemán como gesto de cortesía, por hacer honor a la famosa hospitalidad húngara que, en esta historia, es retratada con mordacidad, poniendo de manifiesto la forma en que dicha actitud de apertura ha sometido a todo tipo de abusos a la nación magiar. La invitada no sólo no hace el más mínimo esfuerzo por aprender una palabra del idioma local o aplaudir la exuberancia de la mesa, sino que aprovecha todas las oportunidades posibles para corregir la más mínima inexactitud en el uso de la lengua germana por parte de los anfitriones o "traduce" al ámbito de lo que ella reconoce como familiar cualquiera de los términos presentados, aunque ello implique despojar a los objetos o las personas de sus atributos distintivos o cualquier rasgo que represente el "sabor nativo". En este contexto, Valkó, el protagonista y cabeza de familia, pide que le acerquen el salero, y nadie atiende su petición. Decidido a alcanzar el doméstico objeto del deseo, estira un brazo y falla en su propósito. La situación se torna cada vez más extrema: cuanto más se esfuerza por alcanzarlo, el salero más se convierte en la encarnación de lo inasequible hasta que, en una ruptura con los referentes realistas y una transgresión radical del sentido de la proporción espacial, el personaje se subsume en una desesperada expedición hacia el salero, corriendo sobre una mesa que ahora es de tamaño gigantesco, mientras todavía se escuchan los ecos lejanos de un festín inmutable, que va quedando cada vez más fuera de las posibilidades de ser descifrado por el protagonista, quien no deja de encogerse (o el mundo no deja de aumentar de tamaño) a lo largo de la historia. El mantel es ahora un campo cubierto por la nieve, y lo improbable se torna deliberadamente posible para crear el efecto del absurdo mientras, de manera aislada, cada uno

\footnotetext{
${ }^{6}$ El primer volumen de Cuentos de un minuto apareció en 1968, año vinculado al nacimiento del postestructuralismo, que acompaña el surgimiento de las estéticas posmodernas. En términos políticos, se trata también de una fecha que atestiguó la configuración de movimientos de resistencia en diversas ciudades del mundo.
} 
de los elementos de la aventura sigue siendo descrito con un cuidadoso "realismo": "He was in luck. He just had to step over the blade of a knife the sizeof a sword to be near his car, a Fiat 1500 . The car was a gift from his brother-in-law, whom some shady business had sent straight to Canada. He opened the door and plopped down behind the steering wheel" (2006: 96-97). ${ }^{7}$

No estamos ante la creación de una realidad paralela, sino ante planos de realidades contenidos en aquella establecida como primer punto de referencia. Las trasgresiones espacio-temporales ocurren por el aumento del tamaño del mundo (desde la perspectiva de Valkó, en la cual está atrapado el lector) y la dislocación de los referentes se torna más violenta por el retroceso, en el tiempo, hacia los recuerdos y fantasías de adolescencia e infancia del personaje, y su materialización en la historia. El protagonista intenta moverse, espacialmente, hacia adelante, pero retrocede, temporalmente, hacia el pasado. Las posibilidades interpretativas generadas por la ruptura con el principio de proporción, el efecto de lo grotesco y lo absurdo son de naturaleza múltiple, y podrían funcionar en el plano de la crisis existencial del individuo, al mismo tiempo que en el nivel de la alegoría política.

Valkó no alcanza el salero. Y como Scott, el expedicionario a quien alude, percibe el entumecimiento de sus miembros, y recuerda la primera vez que sintió deseos de ir a algún lugar: a Italia. Aquí el texto, con la enunciación de la frase "pero el año pasado", nos trae de vuelta al presente del hombre adulto, a la realidad de la Hungría de 1968 (fecha original de composición del cuento), y de manera abrupta menciona los setenta dólares que, en la época de la liberalización de los pasaportes, el gobierno estableció como máximo presupuesto permitido para quienes quisieran viajar fuera del país, lo cual imposibilitaba, de facto, la realización de cualquier traslado. El autor tira del delgado hilo que mantenía la conexión con lo realista y nos obliga a volver al tiempo inicial de la diégesis, donde el absurdo es tan extremo como en la dimensión fantástica más obvia del relato. Podemos decir, incluso, que la sostenida intensidad de lo absurdo y su presencia lo mismo en el plano de la aventura sobre el mantel que en el de la comida en honor de la invitada y, asimismo, en la realidad extratextual aludida por la mención del presupuesto de setenta dólares, produce un desdibujamiento de las fronteras entre planos narrativos y extranarrativos. Éstos son los sacudimientos del realismo fantástico.

Las dislocaciones en la percepción de lo espacial, la incapacidad para comunicarse experimentada por los personajes (aunque emitan parlamentos con oraciones en apariencia coherentes) y la claustrofobia de un mundo donde la posibilidad de elegir es sólo un simulacro son soportables en la prosa de Örkény porque el autor es capaz de incorporar el humor a ese universo narrativo. Sin embargo, recurrir al humor no es aquí equivalente a suavizar o tornar frívolo el ejercicio de la crítica. En la obra de Örkény, la capacidad para reír es una forma de resiliencia. El humor es utilizado por el autor de

\footnotetext{
7 "Estaba de suerte. Sólo tenía que brincar sobre la hoja de un cuchillo del tamaño de una espada para llegar hasta su coche, un Fiat 1500. El coche había sido un regalo de su cuñado, a quien un cierto negocio turbio había mandado directo a Canadá. Abrió la puerta y se dejó caer en el asiento del conductor".
} 
la manera en que lo entendía, también, Nabokov: como un despertar de la conciencia, como herramienta crítica con más de un filo y, a veces, como carcajada en la oscuridad. El protagonista de "In Our Time", un hombre sentado en una cafetería de Buda, dice: "The point is I know what I want. I just can't think of the name. It's a dark liquid" (1995: 58). ${ }^{8}$ Suponemos que lo que quiere es un café, pero le parece que la palabra "café" tal vez no representa de forma cabal a la bebida en cuestión, o simplemente le gustaría poder elegir otra manera de nombrar las cosas. El cuento termina cuando el personaje, exasperado, le dice a la mesera: "'You know what? Why don't you just bring me a cup of coffee?"'(60). ${ }^{9}$ La risa, en esta historia, se adelgaza hasta ser solo mueca. No hay posibilidad real de elegir entre más de una opción, y el lenguaje no logra ser puente entre lo que la mente visualiza y el receptor escucha o lee. El hombre beberá el oscuro líquido de la resignación.

\section{Obras citadas}

BÁN, Zoltán András. 2008. "Fantastic Realism. István Örkény: One Minute Stories". Hungarian Literature Online. Disponible en <www.hlo.hu/news/is tvan_orkeny_100>. Consultado el 29 de abril de 2015.

CORTÁZAR, Julio. 1994. “Aspectos del cuento”. Obra crítica III. México: Alfaguara. ESTERHÁZY, Péter. 2006. "Some Short Paragraphs about a Great Writer”. Prefacio a István ÖRKÉNY. More One Minute Stories. Trad. Judith SollosY. Budapest: Corvina.

Györgyey, Clara. 1989. Búcsú, Review. World Literature Today, vol. 63, núm. 4. Edouard Glissant Issue (otoño). P. 714.

Koves, Margit. 1997. "Telling Stories of Partition and War: Saadat Hasan Manto and István Örkény”. Economic and Political Weekly, vol. 32, núm. 33/34, agosto, 16-29. Pp. 2147-2153.

ÖRKÉNY, István. 2006. More One Minute Stories. Trad. Judith SOLLOSY. Budapest: Corvina.

1995. One Minute Stories. Trad. Judith Sollosy. Budapest: Corvina. 1982. The Flower Show and The Toth Family. Trad. Michael Henry HeIM

y Clara GYÖRGYEY. Nueva York: New Directions Publishing Corporation. 1976. Catsplay: A Tragi-Comedy in Two Acts. Trad. Clara GYörgYeY. Nueva York: Samuel French.

\footnotetext{
8 "El punto es que sí sé lo que quiero, pero no puedo nombrarlo. Es un líquido oscuro".

9 “"¿Sabe qué? ¿Por qué no, simplemente, me trae una taza de café?”"
} 